\title{
A Disrupted Future?
}

\author{
Ian Miles
}

Emeritus Professor, Alliance Manchester Business School ${ }^{\text {a }}$; and Academic Supervisor, Laboratory for Economics of Innovation, Centre for Science and Technology, Innovation and Information Policy, Institute for Statistical Studies and Economics of Knowledge (ISSEK) , imiles@hse.ru

a University of Manchester, Oxford Rd, Manchester M13 9PL, UK

b National Research University Higher School of Economics, 11, Myasnitskaya str., Moscow 101000, Russian Federation

\begin{abstract}
$\mathrm{T}$ The tobacco industry worldwide has annual revenues of hundreds of billions of dollars and annual smoking-associated death rates in the millions. Electronic cigarettes designed as a less harmful alternative to traditional tobacco products allow users to inhale nicotine without consuming the products of burning tobacco, thus significantly lowering health risks. These and similar innovative solutions have a potentially disruptive impact on existing markets. Both newcomers and established cigarette firms have been active around these alternatives. However, the health implications of such products are still poorly studied and seemingly ambiguous. Moreover, there is an increasing number of reports on mass

diseases associated with vaping. As a result, most countries and international institutions, including the World Health Organization, have adopted negative attitudes towards electronic cigarettes.

Do e-cigarettes represent a Trojan Horse that will undermine tobacco control efforts - or are they an effective way to wean users away from cigarettes thus opening the way towards a better future? This paper outlines estimates of the future health impacts of cigarette and e-cigarette use, and considers the broader issues surrounding this potentially disruptive innovation. It points to areas requiring further research and suggests how Foresight studies might address the topic.
\end{abstract}

Keywords: disruptive innovation; e-cigarettes; scenarios; alternative futures; foresight
Citation: Miles I. (2020) A Disrupted Future? Foresight and STI Governance, vol. 14, no 1, pp. 6-27. DOI: 10.17323/25002597.2020.1.6.27 


\section{Introduction}

"Disruptive Innovation" (see Box 1) has become a major theme in innovation studies (how can we explain the emergence and features of high-impact innovations?), and in Foresight exercises (how can we anticipate the implications of potential changes and prepare to make the most of them?). Most innovation studies rely on the comfortable assumption that successful innovations are necessarily ones that benefit humanity. Foresight work, in contrast, often explicitly considers questions of social as well as economic costs and benefits of change. Within innovation studies, climate change and related environmental issues have prompted more researchers to reappraise just what really constitutes a successful innovation.

Neither innovation nor Foresight researchers have paid much attention to one potentially disruptive set of innovations: electronic cigarettes (e-cigarettes). Some observers see these as preventing many millions of early deaths over the course of this century; but others oppose this innovation, even seeing them as making a high death toll more likely.

Many commentators suggest that e-cigarettes are indeed a disruptive innovation, with cigarette smoking patterns being disrupted by new electronic nicotine delivery systems (ENDS). The health consequences of inhaling smoke from tobacco have been exhaustively documented over the last half-century. The World Health Organization (WHO) estimates that there are currently over a billion cigarette smokers in the world today, leading to a huge premature death toll over the course of the century [WHO, 2008]. WHO, and most national public health authorities, have advocated and enacted policies aimed at restricting this toll. But even so, cigarette use is still growing in some regions of the world, though it is generally declining in most industrial countries.

Emerging early in this century, types of e-cigarettes have proliferated. Substantial markets have been created in some countries, though they remain prohibited in many places. ENDS allow smokers to inhale nicotine in a manner similar to smoking, while substantially reducing exposure to the harmful tars, gases, and other harmful substances in cigarette smoke. Forecasts for the USA alone indicate that a large shift to ENDS would avert millions of premature deaths over the coming decades. Unlike many supposedly disruptive innovations, this could be a matter of life or death.

While much of the analysis of disruptive innovations focuses on the challenges to, and responses of, incumbents, other stakeholders can play important roles. In this case, public health officials, the policymakers they advise and the various civil society and campaigning groups come to the fore. The reactions of these groups have been diverse and volatile. This has led to regulatory frameworks and market conditions varying widely across countries and over time. In some cases, the public health movement is resisting innovations that could reduce the harm associated with cigarette smoking. A "tobacco control" philosophy, with a strong distrust of the tobacco industry and aversion to nicotine drives this opposition. In contrast, a "harm reduction" philosophy sees ENDS as reducing preventable deaths well above the levels achieved by tobacco control, even if this means tolerating consumer choices as to whether or not to use nicotine. This essay examines the controversies and uncertainties surrounding this disruptive innovation, and the implications for innovation studies and Foresight activity.

\section{No Smoke without Fire: The Troubled History of Tobacco}

Numerous scholars and journalists have discussed the history of tobacco use, and of the cigarette industry. Thus we provide the briefest of summaries here.

Tobacco use spread from the Americas to the rest of the world from the $16^{\text {th }}$ century on. Smoking has long been one of the most popular ways of using tobacco. Modern combustible cigarettes (with tobacco being rolled up in a paper cylinder) became commonplace in many countries in the nineteenth century, especially after mechanized cigarette rolling systems were introduced. In some developing countries, hand-rolled "cigarettes" remain very popular, e.g. the bidis of rural India. Combustibles became immensely popular by the mid-twentieth century. Marketing promoted their use by women and others for whom cigarette use had been regarded as inappropriate. Such marketing efforts extended beyond advertising: in films and elsewhere cigarettes frequently featured as ubiquitous, as adult and "cool". But in the 1950s, and especially the 1960s, public health organizations in Western countries began to systematically denounce smoking as a source of lung and other diseases.

It is now widely accepted that cigarette smoking is a leading (meanwhile preventable) cause of significant lung, cardiovascular, oncological, and other health-related mortality risks. Lung cancer, a relatively rare disease in the $19^{\text {th }}$ century, has become the "most common form of cancer in the world ... with only a $15 \% 5$-year survival rate for all stages in the United States... Numerous elements have been attributed to the causation of lung cancer; however, none more strongly verified than cigarette smoking" [Ruegg, 2015]. Smoking also plays major roles in chronic obstructive pulmonary disease 
(COPD - a set of diseases including emphysema and chronic bronchitis,) and cardiovascular disease (narrowing or blockage of blood vessels, liable to produce heart attacks, strokes, angina, etc.). The smoke that is created through the combustion of tobacco leaves (and other ingredients) in cigarettes contains a host of unhealthy components. ${ }^{1}$ Smoking's health risks are largely by-products of the particular method of delivery of nicotine provided by cigarettes: nicotine itself is not a major factor.

The tobacco industry contested the evidence of health problems, commissioning studies that appeared to support its position and concealing results that contradicted its claims [Bero, 2013]. It argued that correlation did not prove causation, and that scientists were divided as to smoking's health consequences. Smoking was portrayed as an individual choice. If cigarettes were indeed dangerous, consumers had chosen to take risks (cf. [Kyriakoudes, 2006]). Since, the notion that nicotine was addictive might undermine the case about free in dividual choice, this was also contested. Such persistent obfuscations created widespread distrust of industry pronouncements, especially among public health officials whose anti-tobacco position hardened.

\section{Health Impacts - Now and in the Future}

When launching its MPOWER program of tobacco control in 2008, the WHO declared: "Tobacco kills a third to half of all people who use it, on average 15 years prematurely. Today, tobacco use causes 1 in 10 deaths among adults worldwide - more than five million people a year. By 2030, unless urgent action is taken, tobacco's annual death toll will rise to more than eight million. If current trends continue unchecked, according to various estimates, during this twenty-first century, tobacco could kill up around 500 million to one billion people ...." [WHO, 2008, p. 1, footnotes removed].

More detailed descriptions and forecasts have been developed in the Global Burden of Disease (GBD) Study [Mathers, Loncar, 2006; GBD, 2017]..$^{2}$ Almost a billion people (and one in four men) are currently smokers. If they continue to smoke, half of these can be expected to die prematurely as a result. The issue is shortening of life: GBD estimates an annual global loss of almost 150 million disability-adjusted life-years (DALYs).

The GBD model ${ }^{3}$ takes into account demographic trends and forecasts of economic and social development $^{4}$. (The latter are related to cause-specific mortality rates, estimated from a variety of statistical sources.) This enables a detailed analysis. The prevalence of smoking is declining in most population groups, in most industrialized countries. But $80 \%$ of smokers live in low-income and middleincome countries, in some of which smoking is on the rise. Population growth in some countries with a high level of smoking (China, India, etc.) may well mean that smoking and smoking-related deaths will grow.

The 2006 GBD study produced projections of deaths to 2030 [Mathers, Loncar, 2006]. Tobaccoattributable deaths were calculated, ${ }^{5}$ and projected to grow, from 5.4 million in 2005 to 8.3 million in 2030. This is the baseline scenario estimate more pessimistic and optimistic variants were also outlined, ranging from 7.4 million to 9.7 million deaths projected for 2030. A third of these are cancer-related, with slightly smaller shares accounted for by COPD and cardiovascular disease. Figure 1 graphically represents key projections for deaths attributed to tobacco. Striking differences emerge across world regions - a decline of $9 \%$ in highincome countries, but a $100 \%$ increase in low- and middle-income countries.

The more recent projections, up to to 2060 , do not specifically pull out tobacco-related deaths, but Mathers [Mathers, 2018] draws on the recent GBD to provide projections of deaths from various causes to that date. Age-standardized death rates from most causes (including lung cancer) are forecast to decline. But population growth and ageing mean that total projected deaths are forecast to grow. Figure 2 presents the baseline scenario: here lung cancer grows steadily as a cause of death, to become the most common of the leading causes. Over the course of this century, around a billion lives are expected to end prematurely as a result of smoking. Using the 2015 ratio of deaths to DALYs suggests that some 25 billion years of life (disability-adjusted) will be lost. This is clearly a global

\footnotetext{
Similar risks - notably mouth cancer - are associated with "smokeless tobacco" products such as chewing tobaccos and snuff. A detailed discussion of risks of both smoking and these other traditional products is provided in Chapter 10 of [Stratton et al., 2001].

Up-to-date information on GBD studies is available at https://www.thelancet.com/gbd (accessed 07.10.2019).

3 See https://www.who.int/healthinfo/global_burden_disease/projections/en/ for data in spreadsheet format.

${ }^{4}$ Estimates of trends in years of schooling, for example. The passage of time was taken as a proxy for technological development and health interventions. Economic development was represented by per capita GDP adjusted for purchasing power parity, with World Bank forecasts used to project this.

5 "Tobacco use was measured in terms of "smoking impact" - that component of observed lung cancer mortality attributable to tobacco smoking ... This indirect measure of the accumulated hazards provides a better measure than do current smoking rates for the overall health impact of tobacco, taking into account lag times as well as important aspects of exposure such as duration, type, amount, and mode of smoking ...Smoking impact was calculated for the historical mortality country-year observations by subtracting nonsmoker lung cancer rates from observed total lung cancer mortality rates in the data. ..."' [GBD, 2017, p. 2014] Country-specific projections of smoking levels were produced from regional estimates developed in earlier studies, with some modeling of age-specific smoking levels.
} 
While looking more at the extent to which new technologies involved novel ways of achieving effects, Freeman proposed a distinction between incremental, radical, and revolutionary technological innovations, in terms of their implications [Freeman, 1975]. In furtherance of these ideas, Christensen proposed the idea of "disruptive innovation" to put more emphasis on how far new ways of doing things disrupted markets [Christensen, 1997; Christensen, Raynor, 2003]. The concept of disruptive innovation was used extensively in studies of marketing, strategic management, new product development, and technology management [Danneels, 2004].

Changes in business models might not even require radical new technologies [Christensen, 2006]. When the airline industry was reshaped by the emergence of low-cost "budget" airlines, the new firms ("insurgents") reached less affluent markets, offering low prices with few of the "frills" (meals, hospitality, etc.) with which established airlines ("incumbents") competed. The newcomers did exploit opportunities for online marketing, booking, etc., but technology was not the main issue. The incumbents attempted to introduce their own low-cost brands, but these generally failed to counter the insurgents. Incumbents may find it difficult to restructure their practices in line with the new business models. Markets are reshaped, new firms rise, and the rules of the game are changed, by disruptive innovation. When change, even involving radically new technology, can be easily absorbed with existing business models, then it is seen as "sustaining innovation" rather than disruptive. It will only involve new markets if the innovation can substantially change the offer to consumers, for example by lowering prices.
Christensen argues that disruptive innovations generally offer users cheaper, simpler, and more reliable and convenient goods and/or services [Christensen, 1997]. They may at first find only a niche market, but in moving onto mainstream (mass) markets, they challenge established products and producers, rewriting the "rules of competition" and redefining the key aspects of performance valued by consumers. Incumbents, of course, are liable to fight back to retain their markets. They may try to improve their own product offerings (or at least their marketing), or to persuade regulators or actors in the value chain to limit the challenge from the insurgents.

Juma [Juma, 2016] vividly documents cases where incumbents deploy marketing campaigns and other tactics to portray the innovation as inferior or hinder its entry onto the market for example, on grounds of threatening public health and safety. Taxes or regulations may be mobilized to limit the market acceptance of the innovation. One telling example is the case of margarine, where the dairy industry was able to persuade regulators in some US states to enforce rules specifying that margarine would have to be dyed an unsavory colour, or packaged in black paper. Recently, Mylan et al. [Mylan et al., 2019] have discussed the opposition of the dairy industry to plant-based drinks, including rules preventing them being called "milk" (e.g. soya and almond milk).

Incumbents may alternatively "go with the flow" by acquiring the newcomers or imitating their innovations. If they can accomplish this without major revisions to their business models, they would have achieved sustaining innovations. The situation might well not be a black-and-white one; different business models, and even different markets, may coexist for long periods. problem, even if it is less visible or dramatic than famines, fires, and floods.

\section{Controlling Cigarettes}

Public health authorities (and many other concerned stakeholders) have pursued a number of strategies aimed at reducing use. These include efforts to prevent people from becoming smokers and to aid them in quitting. Information campaigns aim to change awareness, taxes on tobacco products impose financial costs, laws and other regulations may restrict where smoking may take place and how (and to whom) cigarettes can be promoted and sold.

"Tobacco control" measures frequently involve banning smoking in places where others may be exposed to smoke, such as workplaces and public transport. Restrictions are often placed on the advertising and sale of cigarettes, especially to young people. Heavy taxes on cigarettes have become a source of revenue for governments, while initiatives such as helplines and other assistance for users hoping to quit require expenditure. Such 
Figure 1. Projections of Global Tobacco-Caused Deaths in 2002-2030 in Three Scenarios
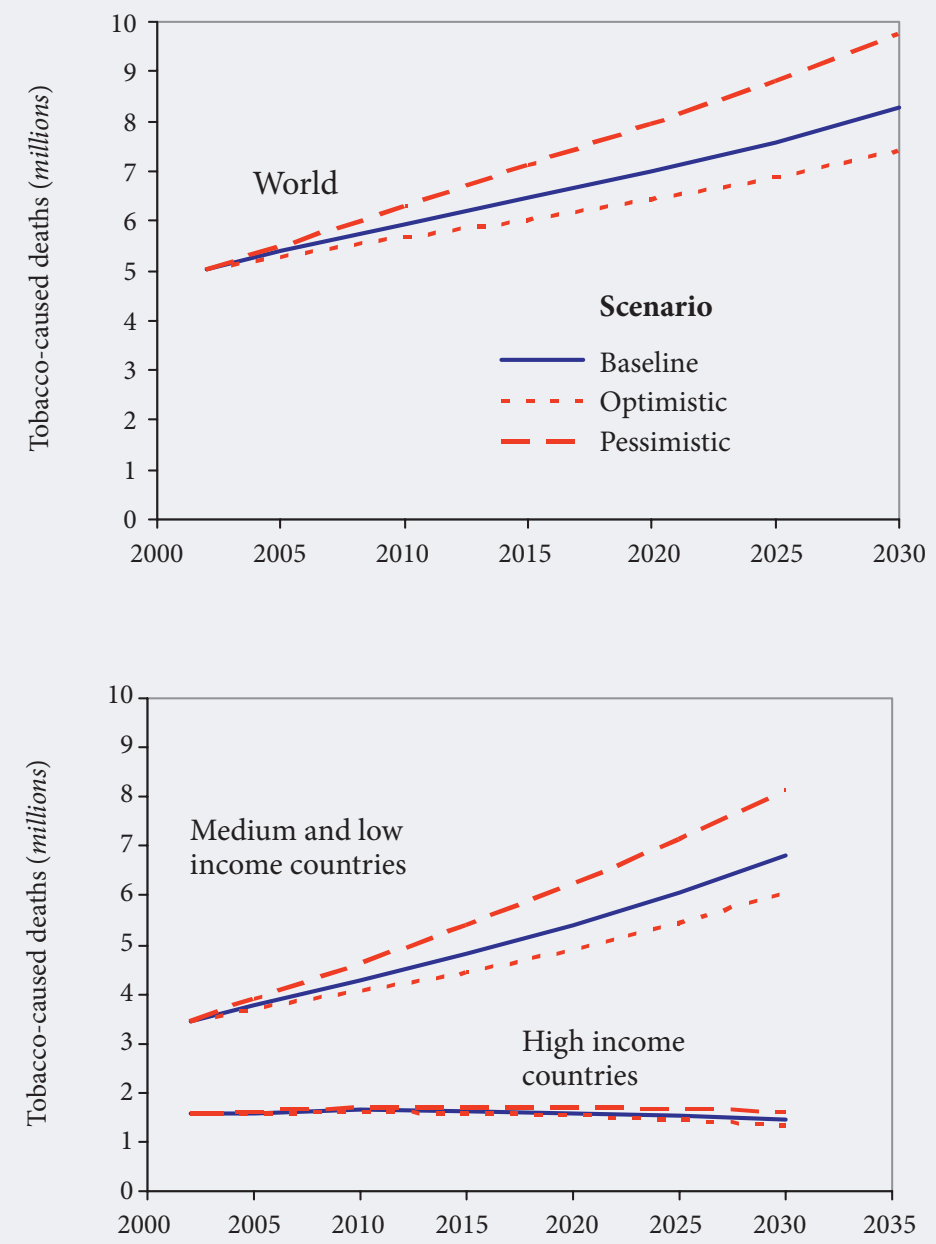

Source: [Mathers, Loncar, 2006].

\section{Figure 2. Projections of Global Deaths from Major Causes, 2000-2060}

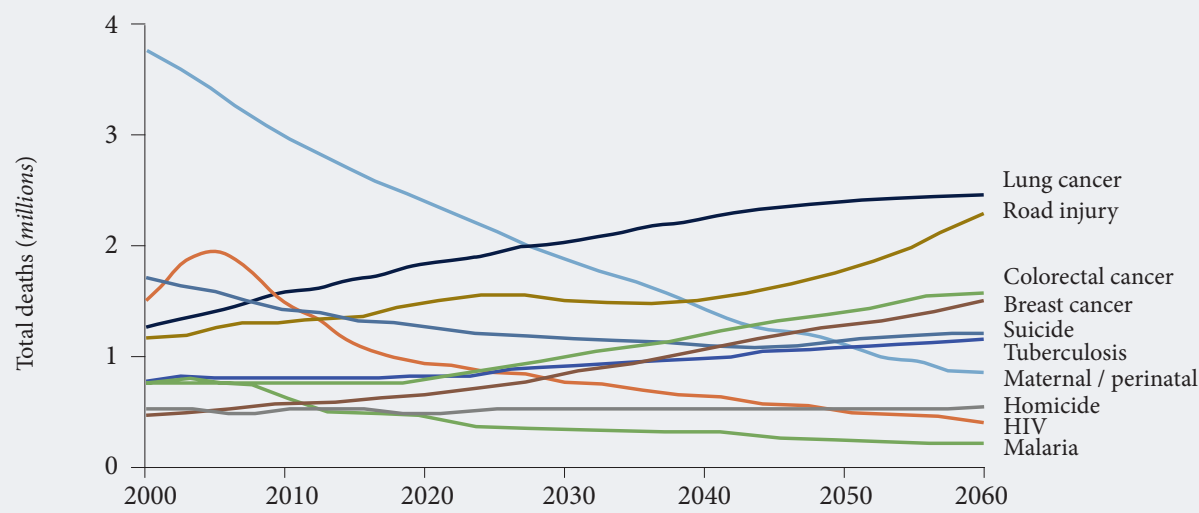

Source: [Mathers, 2018]. 
Instead of using tobacco, ENDS devices supply nicotine in a liquid solution (commonly based on propylene glycol, and often including flavorings). This is vaporized, giving rise to the terms "vape" and "vaping". The idea is to achieve an experience similar to that of cigarette smoking, but with a huge reduction in the harmful substances produced by combustion. If this can be achieved, then ENDs can in principle disrupt markets, taking sales away from cigarettes to less harmful alternatives.

While there had been earlier patents and experiments, the successful commercial exploitation of this idea was first achieved in China. Industry lore has it that Hon Lik (who worked for Golden Dragon Holdings, a company producing ginseng products) was inspired to design a safer product than the combustible cigarette following his father's lung cancer. He patented an e-cigarette design in 2003 (internationally patented in 2007). His firm commercialized this in 2004 on the Chinese market, changing its name to Ruyan ("like smoke"), and exporting ENDS from 2007. According to the US Surgeon General [Surgeon General, 2016, p. 10], "In August 2013, Imperial Tobacco Group purchased the intellectual property behind the Ruyan e-cigarette for $\$ 75$ million. As of 2014 an estimated $90 \%$ of the world's production of e-cigarette technology and products came from mainland China, mainly Guangdong
Province and Zhejiang Province." Hon Lik himself joined the e-cigarette company Fontem Ventures, a subsidiary of the tobacco company Imperial, in 2013. Fontem is responsible for the e-vapor brand $b l u$; according to blu's website Hon Lik aims to continue development and innovation in the area.

Other manufacturers were quick to introduce copies of, and variants on, the design [Surgeon General, 2016]. The rapid evolution of ENDS' designs reflects, at least in part, the fast growth of markets for the products, and various dynamics within this market. Williams and Talbot [Williams, Talbot, 2019] identify four generations, differing in terms of the e-cigarette itself (its external form and appearance, e.g. whether it looks like a traditional cigarette or is more like an iPod or other device; and the battery characteristics, including "Mods" (consumers can vary voltage, wattage, and power via modified batteries) and on the atomizing units used in the ENDS. In common, they can deliver not only nicotine, but also much of the same experience as cigarette smoking, including the taste, ease of inhalation, and so on. The aerosols can be flavored in different ways. Different products have gained substantial footholds in different countries. Many new entrants are manufacturing vape liquids and devices, and retail outlets in the form of "vape stores" have proliferated in many countries. measures have been instituted in many countries and are promoted by WHO's MPOWER program. ${ }^{6}$ They are seen as having enabled the substantial long-term decline in the rates of smoking in most industrial countries (and some cases elsewhere, notably Brazil). But the decline in smoking is uneven globally. The GDB forecasts suggest that despite tobacco control measures, cigarettes will lead to massive mortality over the course of this century. WHO calls for a redoubling of efforts and denounces the tobacco industry's ongoing promotion of cigarettes (especially in low-income countries and to young people).

Facilitating cessation is the other part of the strategy. Many users are dependent on nicotine, finding it difficult to relinquish or even reduce the smok- ing habit. A variety of medical ways of addressing the problem have been attempted [Aveyard, Raw, 2012]. These include pharmaceutical treatment: drugs such as cystine and varenicline reduce the effect of nicotine on the brain, rendering smoking less pleasurable. To date, attempts to develop vaccines that counteract addiction (which have proven promising with some other drugs) appear to have been unsuccessful (for an interesting sociological study of these efforts see [Wolters, 2017]). Since the tars and other results of combusting tobacco are the main source of damage to the health of users (and others exposed to the smoke) nicotine replacement therapy (NRT) is widely used. NRT delivers nicotine through wearable patches, or sweets or gums.

\footnotetext{
${ }^{6}$ See https://www.who.int/tobacco/mpower/publications/en/ (accessed 09.10.2019) and related WHO resources for explication of tobacco control programs, success stories, statistics concerning the uptake of various measures, and so on.
} 


\section{A Disruption?}

Many attempts have been made over the years to create cigarette products that involve or, at least, that appear to involve lower risks. Cigarette manufacturers have introduced and promoted, for instance, filters, and "mild" and "low tar" cigarettes. Some of these products, which can be seen as efforts to apply incremental innovation to preserve the established order, have been commercial successes. In general they do not substantially reduce risks - and in some cases increase them (e.g. by enabling smoke to penetrate further into the lungs) [Song et al., 2017]. ${ }^{7}$

Conventional cigarettes are "combustibles", burning tobacco and releasing nicotine in the smoke created - which also contains substances associated with health problems for users and passive smokers alike. Recognizing this, a more dramatic innovative effort involved the introduction of "Heat Not Burn" (HNB) products. These use batteries to heat tobacco (to temperatures well below those reached by burning it) so that nicotine vaporizes and can be inhaled. ${ }^{8}$ Other substances are also vaporized. There has been controversy about the extent to which carcinogens are involved - something that is liable to vary across different HNB products. Tobacco companies introduced HNB devices in the 1980 s, but these made little market impact. Users criticized their appearance, cumbersome features, and the taste and feel of the smoking experience. Marketing them as "safer" alternatives was also difficult, as it meant conceding that combustible cigarettes were unsafe, and raised issues with regulators. ${ }^{9}$ HNB technology has recently been revived, as we shall see below.

The prospects for a disruptive technological innovation increased dramatically in the present century, with the emergence of e-cigarettes, ENDs. Unlike HNB (and, of course, traditional combustible cigarettes), ENDS do not use tobacco leaves (see Box 2), but still supply nicotine and an experience much like cigarette smoking.

During the 2010s, many voices suggested that ENDS could be disruptive to tobacco industries. For example, Citigroup presented e-cigarettes as a leading case in the very first issue of its annual series on disruptive innovations [Spielman, Azer, 2013]. More recently, Euromonitor took the e-cigarette firm Juul as a prime example of "Insurgent Brands". Juul Labs is described as follows:

"the product of an independent nicotine delivery and vapourisation device start-up" that has "reconfigured the global nicotine landscape. It created a new category...[it] drove declines in the value of major tobacco company shares and provoked strategic revisions such that the USA's leading tobacco company jettisoned all its existing e-cigarette offerings. JUUL Labs raised US $\$ 1.2$ billion in funding in June 2018, valuing the company at US\$16 billion. Just 6 months later, Altria ${ }^{10}$ bought $35 \%$ of JUUL Labs for around US $\$ 13$ billion valuing it at US $\$ 38$ billion.... Although the market for vapour products remains a fraction of that for cigarettes, the growth trajectory of both categories is very far apart. We expect to see $20.1 \%$ real growth in retail sales in value terms of vapour products in 2018, compared to $0.4 \%$ for cigarettes." [Brehmer, Boumphrey, 2019, p. 10].

The largest markets for ENDS are generally reported to be the USA and then the UK (e.g. WHO, 2016). According to BBC news reports [Jones, 2019], Euromonitor (a market research firm) estimated recently that the worldwide growth in the number of people vaping over the period 2011-2018 was from about seven million to some 41 million. They forecast 55 million users in 2021 - still only around 5\% of the number of users of combustibles. The global market was estimated as being over $\$ 19 \mathrm{bn}$, with the largest components being the USA (c $\$ 7 b n)$, UK (c $\$ 3 b n)$, followed by France, Germany, and China (each under $\$ 2 \mathrm{bn}$ ). This compares with much larger figures for the global cigarette market size, where estimates involve hundreds of billions of dollars. ${ }^{11}$ But Euromonitor's data do indicate that in terms of "value" (i.e. sales) vaping products in 2017 saw a growth of $50.7 \%$, as opposed to $2.8 \%$ for combustible cigarettes, while in terms of "unit volume growth" 12 the respective figures were $36.8 \%$ and $-1.4 \%$ [FSFW, 2018]. These radically different growth rates suggest that a disruption in the cigarette landscape may be underway.

\footnotetext{
7 These strategies, and other efforts to remove poisonous substances from tobacco, are discussed in detail in [Parker-Pope, 2001].

8 There have been some concerns over the safety of the batteries used in these devices and a number of reports of explosions associated with these. For a discussion of injuries associated with such explosions see [Rossheim et al., 2019].

9 For a discussion of the early HNB experience under the rubrics of "High-tech Cigarettes" and "Smokeless Smokes" see [Parker-Pope, 2001].

${ }^{10}$ Altria (formerly Philip Morris), with a revenue in 2018 of over \$25 billion, is one of the world's largest tobacco companies, and currently holds a c50\% market share of cigarettes in the USA.

${ }^{11}$ See for example the report at https:/www.statista.com/statistics/259204/leading-10-tobacco-companies-worldwide-based-on-net-sales/ (accessed 13.10.2019), which also reports that the biggest firms in sales terms are Philip Morris International (2018 sales of nearly \$30bn), British American Tobacco (over \$26bn), Imperial Tobacco, Altria, and Japan Tobacco all around $\$ 20 \mathrm{bn}$. It should be remembered that consumer prices for cigarettes vary considerably around the world, so some of the heaviest concentrations of smokers are based in countries that appear to have relatively small tobacco industries in terms of turnover; and some markets are served by artisanal production (e.g. of "bidis" rather than manufactured cigarettes in India).

${ }^{12}$ The individual "cigarette stick" and equivalents to this, were used as the unit.
} 


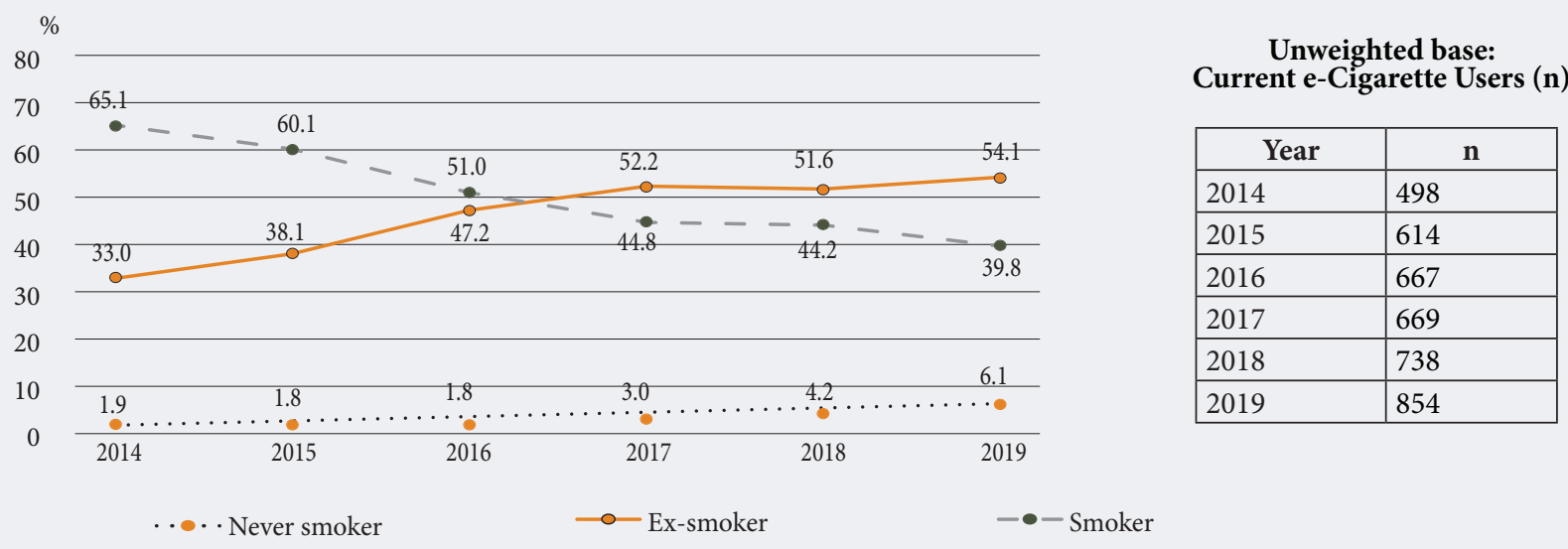

Note: Over this period the proportion of the adult population who are current ENDS users grew from $4.2 \%$ to $7.1 \%, 2.1 \mathrm{~m}$ to $3.6 \mathrm{~m}$.

Source: [ASH, 2019].

The use of data from a market research company Euromonitor reflects in part the fact that only a few countries have accurate data on these phenomena. Especially valuable would be data that indicate whether people are shifting from combustible to electronic cigarettes, using the two as complements, or (most controversially) initiating nicotine consumption via ENDS.

The statistics for UK provide some relevant data. The Office for National Statistics [UK ONS, 2019] reports an ongoing decline in the number of UK adults who were current cigarette smokers, from $20.2 \%$ of the adult population in 2011 to $14.7 \%$ in 2018. Cigarette use has been monitored by the Opinions and Lifestyle Survey ${ }^{13}$ from 1974, with e-cigarettes studied from 2014. Over 2014-2018, vapers rose from $3.7 \%$ to $6.3 \%$. of the adult population. More than half of these said they vaped to help themselves quit smoking; just under a third because they saw vaping as less harmful than smoking. A detailed analysis of these and other survey data is presented by Public Health England [McNeil et al., 2019], where among the points made are:

- The majority of adult vapers are ex-smokers.

- ENDS have not interrupted the downward trend in uptake of cigarettes.

- The prevalence of vaping does not seem to be on the rise since 2015 (some commentators relate this to widespread views that e-cigarettes are as unhealthy as combustibles ${ }^{14}$ ).
- Members of higher socioeconomic groups are less prone to smoke and are more likely to vape in order to quit smoking, while those from more disadvantaged groups are more likely to continue to smoke.

- The uptake of ENDS among non-smokers is very low - less than 5\% of vapers are "never smokers", though there is a possibility that this figure is increasing (see the lowest trend line in Figure 3, which adds more recent data).

These conclusions suggest that ENDS are indeed potentially disruptive, in the sense of users actually moving away from combustibles. The ambition of many vapers is to move away from nicotine altogether. Some vapers, however, have become a subculture, holding annual conferences, competitions about being able to blow the most impressive "smoke" rings, and the like (a striking journalistic report is [Usborne, 2018]). ${ }^{15}$

Consumers are expected to adopt disruptive innovations if these are felt to offer more benefits and/or fewer costs. If ENDS are to be more than a niche innovation, they have to provide the pleasure to the consumer (benefits), while reducing the costs (health risks). Consumer beliefs about health risks will be influenced by messages from credible sources, such as scientific authorities (though their messages are mediated through reporting in mass media, press releases, and the like). What do we know about health risks of ENDS?

\footnotetext{
${ }^{13}$ Of adults aged 16 years and above in Great Britain - this excludes Northern Ireland.

${ }^{14} \mathrm{ASH}$ [ASH, 2019] present data showing an increase from $7 \%$ in 2013 to $25 \%$ in 2017 in the proportion of the adult population thinking that e-cigarettes are "more or equally harmful as smoking".

${ }^{15}$ For data on the situation concerning smoking, regulation, ENDS, and THR see https://gsthr.org/global-data/ (accessed 14.11.2019).
} 

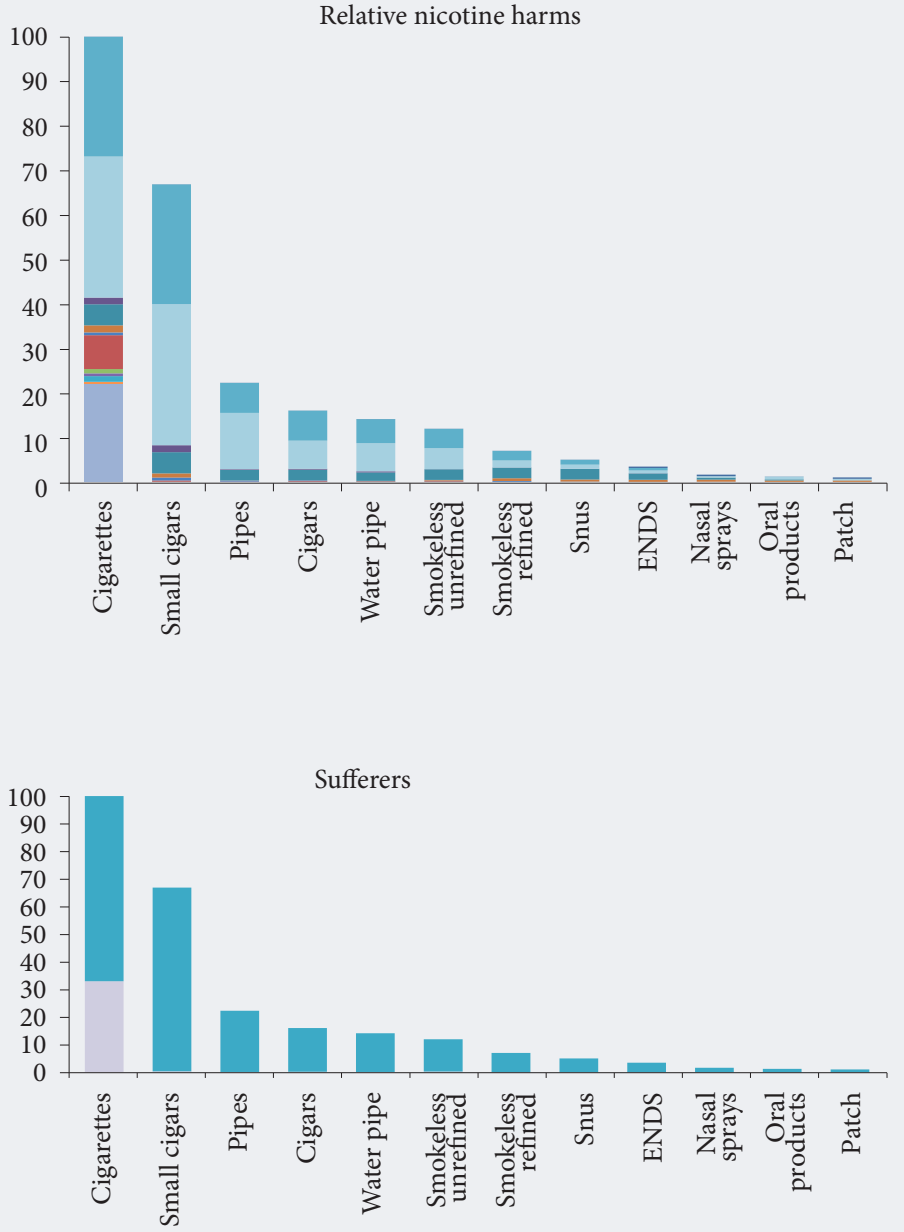

Product-specific mortality -0.3

- Product-related mortality -27

Product-specific morbidity -32

- Product-related morbidity -2

- Dependence - 5

Loss of tangibles -2

- Loss of relationships - 1

- Injury -8

Crime -1

Environmental damage - 1

- Family adversities -1

International damage - 0.3

- Economic costs - 22

Community -0
Users -67
Others -33

Notes: the "smokeless" categories are chewing tobaccos; snus is a different chewing product used primarily in Nordic countries.

Source: [Nutt et al., 2014].

\section{Health Risks and ENDS}

Only a few studies directly compare ENDS use with smoking combustibles. Stephens [Stephens, 2017] examined the emissions from (one type of) ENDS, cigarettes, an HNB device, and a medical inhaler for nicotine. Stephens reported that while aerosols from ENDS contained various carcinogens, these were mostly at less than $1 \%$ of the potency of tobacco smoke. (When excessive power was delivered to the ENDS coil, high levels of some carcinogens would be released.) Medical inhalers were seen as posing least lifetime risk associated with carcinogens, followed by ENDS, then HNB, and finally combustibles. Note the implication that
ENDS devices and applications may vary in health impacts - as designs proliferate, we may be less able to make generalizations. ${ }^{16}$ Ideally, innovation would be directed towards lower health impacts: technological possibilities, regulations, and market demand all have roles here.

A second study, Chen et al [Chen et al., 2017], compared ENDs with combustibles, using the U.S. Environmental Protection Agency's methodology for human health risk assessment. Twelve toxicants earlier identified as posing the greatest health risks were used as assessment criteria, and the estimates of exposure calculated, assuming similar usage patterns of ENDs and combustibles. Both practices

\footnotetext{
${ }^{16}$ This is confirmed by NASEM [NASEM, 2018, p. 6]: "Conclusion 5-2. There is conclusive evidence that, other than nicotine, the number, quantity, and characteristics of potentially toxic substances emitted from e-cigarettes are highly variable and depend on product characteristics (including device and e-liquid characteristics) and how the device is operated." Cf., "Conclusion 5-3. There is substantial evidence that except for nicotine, under typical conditions of use, exposure to potentially toxic substances from e-cigarettes is significantly lower compared with combustible tobacco cigarettes."
} 


\section{Figure 5. Estimates of Impacts in the USA of a Shift (over 2016-2016) from Combustibles to ENDS}

a) Point projections, all age cohorts and both sexes combined
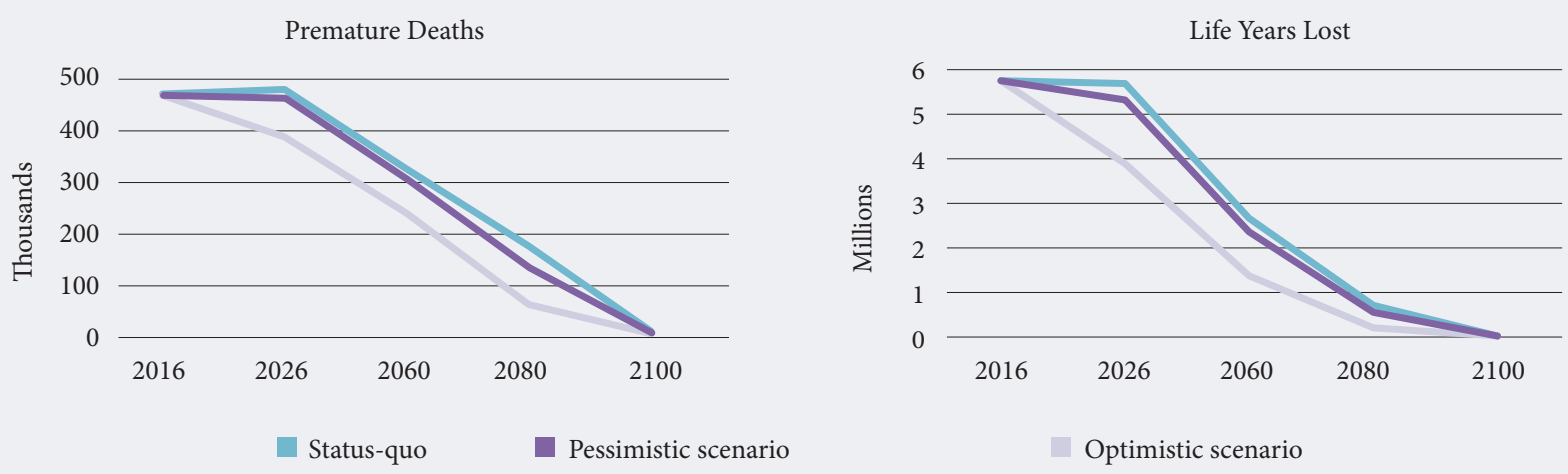

b) Cumulative Estimates, 2016-2100

Cumulative Premature Deaths

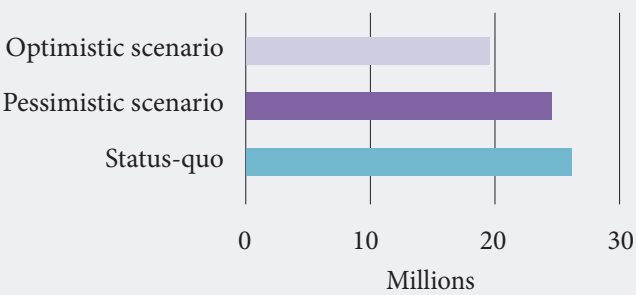

Cumulative LYLs

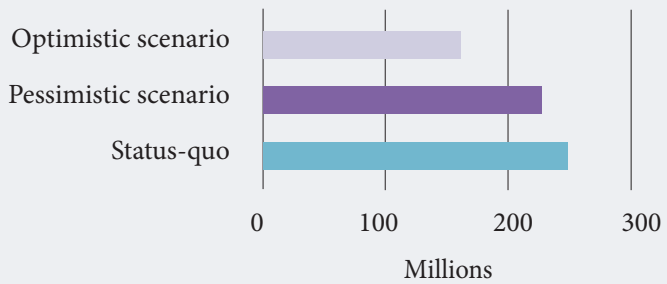

Source: based on data presented in [Levy et al., 2018].

were found to have health risks, but combustibles posed much higher risks. Low quality ENDS were liable to be more problematic than devices with higher manufacturing and quality standards. These authors conclude that switching to high-quality ecigarettes has the potential to save millions of lives.

A major review of evidence was undertaken by an expert group for the National Academies of Science, Engineering and Medicine. Its first conclusion as to harm reduction was "Conclusion 18-1. There is conclusive evidence that completely substituting e-cigarettes for combustible tobacco cigarettes reduces users' exposure to numerous toxicants and carcinogens present in combustible tobacco cigarettes." More explicitly “... across a range of studies and outcomes, e-cigarettes pose less risk to an individual than combustible tobacco cigarettes" [NASEM, 2018, p. 11].

In 2014, the UK-based Independent Scientific Committee on Drugs convened an international expert panel (spanning a range of disciplines) [Nutt et al., 2014]. Multicriteria Analysis - a method familiar in Foresight studies - has been adopted to bring together expert opinion in order to address the likely health (and other negative) implications of different routes for nicotine delivery. The experts discussed various products and types of harm, and then assessed each of the 14 harms occasioned by 12 products. Both harms to the user and harms to others were addressed with seven items each. Each criterion was also assessed in terms of relative importance. Ratings were made on a $0-100$ scale, with 100 referring to the most harmful product on a given criterion, and 0 defined as no harm. As Figure 4 indicates, cigarettes and small cigars were seen as far more potent sources of harm than other nicotine delivery systems. This study was employed in a widely cited reference point for assessment. In the subsequent debate concerning this study, the authors suggested that one simple way of interpreting the result is to see e-cigarettes as twenty times less harmful than combustibles [Nutt et al., 2016].

What would it mean for health if the disruptive innovation actually were to prove successful? Clearly, in addition to the actual reduction in health risks, such factors as speed of diffusion/substitution, similarity of usage patterns, effects on rates of complete cessation of nicotine use, will need to be taken into account if forecasts are to have much grounding in plausible trends. Sophisticated mod- 


\section{Figure 6. Scenarios for Impact on Life Years Lost in the USA}

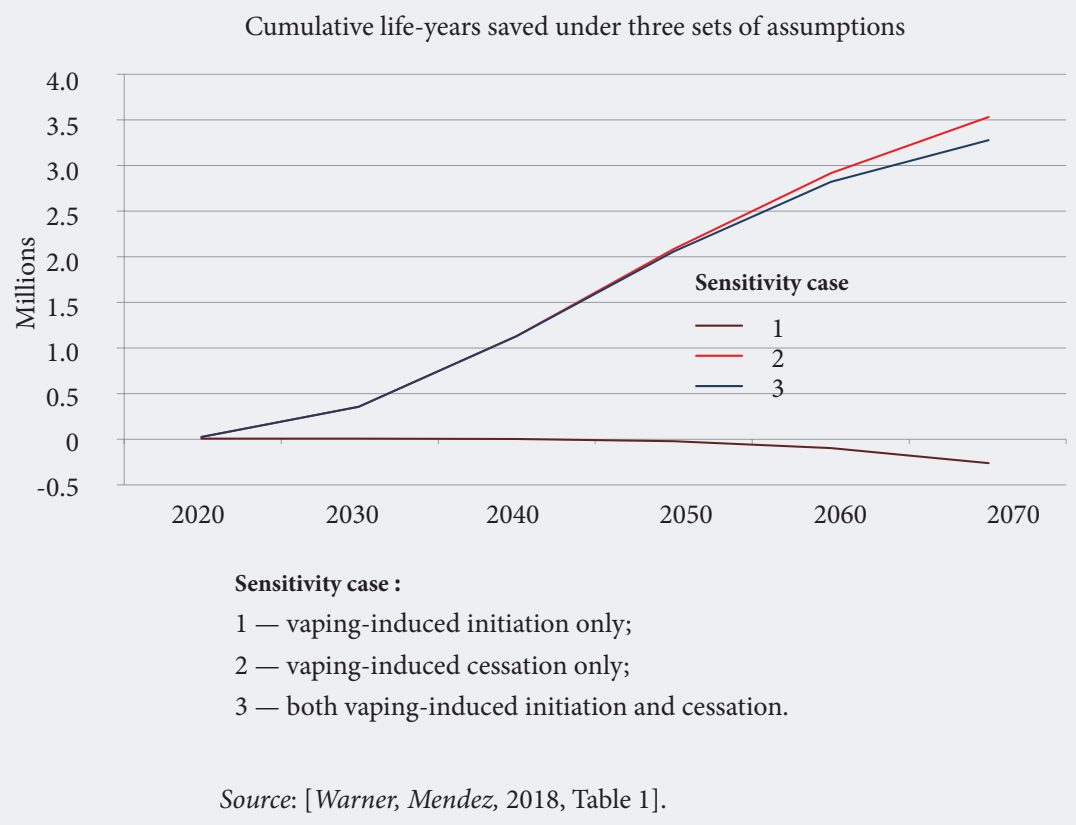

eling is undertaken within the tobacco industry (e.g. [Lee et al., 2017; Djurdjevic et al., 2018], which is evidently attentive to future market prospects. Steps toward assessing health impacts of a shift to ENDS are presented by [Levy et al., 2018], who examine the US situation until 2100. Mortality and LYL (life years lost) are compared across a Status Quo scenario and Optimistic and Pessimistic scenarios. In the Status Quo scenario, smoking rates (from 2016) were projected forward, using data on rates of smoking initiation and cessation based on 1965-2012 data for different ages and sexes. The Optimistic and Pessimistic scenarios differ in three respects. First, residual cigarette smoking is merely $5 \%$ of the Status Quo value in the former, while in the latter it is $10 \%$; the transition to these levels is assumed to take 10 years. Second, the initiation of uptake varies across scenarios; in the Optimistic scenario the initiation of e-cigarette use is assumed to be at the same rates (by groups) as is the initiation of cigarette use in the Status Quo Scenario, after reaching a 5\% smoking prevalence. In the Pessimistic Scenario, it is assumed that nicotine use has become more "normalized" as a result of e-cigarettes; ENDS initiation is assumed to occur more rapidly (150\% of the Status Quo scenario's smoking initiation rate). Third, the Optimistic Scenario, takes the excess risk of ENDS as being 5\% that of cigarette use, while the Pessimistic scenario assumes it to be $40 \%{ }^{17}$

Figure 5 provides a visual representation of the overall implications of the scenarios. They converge in terms of premature deaths and life years lost by 2100 . However, over the course of the 84 years the Pessimistic Scenario yields 1.6 million premature deaths averted, some 20.8 million fewer life years lost compared to the Status Quo. The Optimistic Scenario features 6.6 million fewer premature deaths and some 86.7 million fewer LYLs. These cumulative outcomes imply that a huge disease burden could be alleviated by a mass shift from combustibles to ENDS. (More detailed analysis, examining the relative experience of different age and sex groups, shows, for example, that the greatest impact of the shift to ENDS in the USA would be among younger cohorts).

A far wider range of assumptions for the modeling of LYL outcomes (to 2050 and 2070) was developed by [NASEM, 2018]. This compares various assumptions, many of them quite extreme, as to (a) the relative harm of e-cigarettes compared with combustibles (from 0 to $50 \%$ of the harm, (b) their potential effects on rates of initiation of combustible use (from neutral to a 50\% increase), and (c) on cessation of combustible use (from a reduc-

${ }^{17}$ The model takes into account the effects of people moving from being smokers to becoming vapers, as well. 
tion of $-5 \%$ to increases of up to $15 \%)$. A total of 85 different combinations of these assumptions were explored. Some of these suggest major savings in LYLs, because ENDS offer only benefits. Others present far more threatening outlooks. For example, if ENDS substantially promotes initiation of smoking, then this leads to greater mortality and LYL in later years. (The benefits of increased net cessation emerge more immediately than the negative effects of increased initiation. Example: even if ENDS cause no harm directly, if they increase the rate of initiation of smoking by one-quarter, while increasing net cessation by 5 percent (to 4.57 percent) in 2015 , a saving of nearly a million LYLs by 2050 would amount to a net loss of over half a million LYLs by 2070.) The conclusion that ENDS might be positive for public health over immediate decades, but negative in the longer term, achieved much publicity. But the NASEM's own summary states that "The modeling results suggest that, under likely scenarios, the use of e-cigarettes in the population will result in a net public health benefit....Under extreme adverse assumptions, the modeling projects a net public health loss." ${ }^{18}$ Even under assumptions that ENDS present $10 \%$ of the risk of combustibles increasing the initiation of smoking by $10 \%$, while that of cessation is only $5 \%$, the worse of the scenarios thought likely, the reduction in LYLs from 2012-2017 was 1 million. In the best of these scenarios, the saving of LYLs was over six times this amount.

Warner and Mendez [Warner, Mendez, 2018] also consider also effects of ENDS on initiation and cessation of smoking of combustibles, in US scenarios to 2070. In a "Status Quo" scenario derived from historical data and assuming no introduction of ENDS, the background initiation rate falls from $20 \%$ in 2010 to $10 \%$ in 2028 , and the background cessation rate increases from $4.18 \%$ in 2010 to $6 \%$ in 2028. ${ }^{19}$ LYLs from this status quo are then compared with those for three scenarios - "sensitivity analyses". All of these feature assumptions that are "biased against finding a net benefit from vaping - to test the robustness of base-case findings" [ibid., p. 43]. Sensitivity analysis 1 simply assumes that every smoker who quits smoking as a result of vaping loses $10 \%$ of the mortality reduction associated with quitting smoking outright. Analysis 2 assumes a vaping-induced initiation rate increase of $6 \%$, three times what the authors estimated would be the most likely effect. Analysis 3 combines the increases of $6 \%$ in initiation rate and $5 \%$ in cessation rate, and the loss of $10 \%$ of the mortality reduction associated with quitting smoking with- out vaping. Figure 6 illustrates the results of these three analyses.

These scenarios indicate that benefits for public health of ENDS from helping cessation far outweigh the costs associated with vaping inducing additional young people to become smokers. Warner and Mendez see this conclusion as being consistent with those of most other published modeling studies. In contrast with [Levy et al., 2018] with a potential gain by 2100 of tens of millions life-years, Warner and Mendez estimate by 2070 a net gain of 3.3 million life-years. They see this as reflecting the former study having outlined scenarios in which vaping replaced smoking entirely within a decade - an immense disruption - while their study considered "evidence-based marginal vaping-induced changes in initiation and cessation" [Warner, Mendez, 2018, p. 44]. Though the estimated net benefits are only a small fraction of the huge toll of smoking-related LYLs, this small fraction remains a remarkably serious figure in terms of public health.

These modeling studies, furthermore, only consider the USA. Should analysis of this sort be extended to other countries and regions, the global figures would doubtless be enormous. In areas where cigarette use is not (yet?) declining, the impact of ENDS could be even more striking. However, the shift to ENDS use might be more problematic, since the current prices of the new devices are practically prohibitive for many consumers in some of these areas.

\section{Responding to Disruption}

Tobacco companies have not been complacent in the face of this threat. One strategy is illustrated by the cases of blu (Imperial) and Dragonite, as well as Altria and Juul, mentioned above. Some leading incumbents have acquired ownership, or partial ownership, of major insurgents. The Surgeon General's report [Surgeon General, 2016, Table 4.3] featured over 20 acquisitions or partnerships between established firms and ENDS newcomers before the end of 2015. Clearly, these incumbents perceived a realistic challenge from the disruptive innovation. A cover story published by Newsweek in May of that year highlights the British American Tobacco case [Newsweek, 2015].

Another strategy has been to develop their own alternative products. This would be in line with earlier efforts to overcome health-related concerns. Thus, Philip Morris International (PMI) is currently marketing IQOS, a novel Heat-Not-Burn product that has proven much more successful than ear-

\footnotetext{
${ }^{18}$ This formulation is on slide 40 of the presentation accompanying [NASEM, 2018], available at: https://www.nap.edu/resource/24952/NASEM-E-CigsWebinar-Slides.pdf (accessed 17.12.2019)

${ }^{19}$ Initiation and cessation rates stay at 2028 levels thereafter.
} 
lier attempts at HNB. IQOS was launched in Japan in 2014 and now has a presence on several other markets, including the USA (where it launched in October 2019 having gained regulatory approval). ${ }^{20}$ British American Tobacco (BAT) offers an HNB product, "glo": both IQOS and glo are permitted and on sale in shopping malls in Russia.

Parts of the established tobacco industry, then, have sought their own sustaining innovations (HNB). Parts have accommodated themselves to the disruptive technology, often partnering with the new competitors. The situation remains in flux, with different firms pursuing different (and sometimes multiple) strategies, while there is also much variety across different countries. China is an outstanding exception. China features a distinctive market situation. The tobacco industry is effectively a state-owned enterprise (cf. $[L i, 2012]$ ). Cigarette prices, and consumer awareness of the health risks of smoking, are low by international standards [ITC, 2017; Horwitz, 2019]. A comparison of web coverage on ENDS in China and the West notes a lack of online information from public health authorities in China (Chen et al, 2020). China has the world's largest smoking population: over 300 million smokers [ITC, 2017]. Over a million people die annually in China from smokingrelated diseases; a figure forecast to treble by 2050 unless more substantial steps are taken to reduce that toll [ITC, 2017]. Ironically, given the "invention" of contemporary ENDS in China, and the presence of Chinese firms on international markets - the vaping population is low. Journalists report that China Tobacco is exploring HNB products, while e-cigarettes are coming under tighter regulation [Horwitz, 2019; Kirton, 2019].

Not only do industry and regulatory structures vary across countries, as do markets: the cost of ENDS or HNB systems may be problematic for poorer people, especially in poorer countries. Where ENDS are available, new firms and supply chains have arisen and continue to evolve. New complementary suppliers offer their own "mods" 21 , as well as vaping liquids, flavors, and cartridges. One important element is that of "user innovation" (e.g. enthusiasts modifying battery features of ENDS devices). In some cases, there are illicit products and markets, including vapes whose critical ingredient is not nicotine, but substances derived from cannabis or "designer drugs".

An important role in the evolution of markets for combustibles and alternatives is played by regulators and public health organizations. In some instances, these bodies welcome a less harmful alternative to cigarettes and celebrate disruption. In many other cases, they are hostile.

There are several elements to this hostility. While many proponents of vaping have seen the innovation as a challenge to "Big Tobacco", champions of tobacco control see the growing ties between cigarette firms and the insurgents as evidence that "Big Tobacco" has found a new battlefront. Proponents of tobacco control have long been locked in verbal conflict with those opposed to regulation. Tobacco firms engage in various ploys, not least disputing the scientific evidence of strong links between smoking and ill-health and denying that nicotine was addictive. A visceral reaction to tobacco companies leads to suspicion about anything they advocate. It is hard enough to restore faith in an individual corporation, but practically an entire industry is tarred here (no pun intended).

A second set of reasons to resist the innovations portrays ENDS as a Trojan Horse. Vaping may be a "gateway drug", leading people (especially young people) towards cigarette use, via addiction to nicotine, and the normalization of smoking [Chapman, Wakefield, 2013]. ${ }^{22}$ These ideas are disputable; critical analyses of the "gateway theory" include [Etter, 2017; Bell, Keane, 2014; Phillips, 2015]). Evidence that ENDS use risks undermining the gains of tobacco control is ambiguous. In the USA, in particular, there has been considerable concern expressed about young people's adoption of e-cigarettes, with Juul portrayed as a major villain. In contrast, Public Health England concludes that vaping is often pursued as a route out of smoking and supports the UK's combination of strict product regulation and relatively liberal policy concerning sales to adults. [McNeill et al., 2018] present the latest evidence review on the topic. ${ }^{23}$

A third set of reasons relate to the possible health hazards of ENDS. Since these are fairly new tech-

\footnotetext{
${ }^{20}$ According to https://www.pmiscience.com/our-products (accessed 15.11.2019) PMI is developing "four smoke-free product platforms, two of which are heated tobacco products and two are e-vapor products".

${ }^{21}$ Users modify ENDS devices so as to achieve different results (e.g. the production of visible vapor, the inhalation of different aerosols). An idea of the large range of "mods" that are available can be gained from the products featured at https:/vaping360.com/best-vape-mods/ (accessed 02.11.2019).

${ }^{22}$ An echo of this viewpoint, which is bound to alarm public health officials and reinforce the view of tobacco industry intentions to profit from HNB and ENDS is provided by British American Tobacco in a guide for investors in March 2019 [British American Tobacco, 2019].

${ }^{23}$ The UK Government's position, in the section on e-cigarettes at https://www.gov.uk/government/publications/health-matters-stopping-smoking-whatworks/health-matters-stopping-smoking-what-works (published 25.09.2018; accessed 21.11.2019), includes the statements: "Leading UK health and public health organisations ... agree that although not risk-free, e-cigarettes are far less harmful than smoking. ...E-cigarettes are currently the most popular stop smoking aid in England.... Over half (51\%) have stopped smoking completely and of the $45 \%$ who still smoke, half say that they are vaping in order to stop smoking... There is growing evidence that e-cigarettes are helping many thousands of smokers in England to quit. The available evidence from research trials suggests that their effectiveness is broadly similar to prescribed stop smoking medicines and better than NRT products if these are used without any professional support..."
} 
Over the course of 2019, reports began emerging - almost exclusively in the USA and later Canada - of users of vaping devices suffering serious lung problems (a condition called "popcorn lung", which can be fatal). The figure below indicates the emergence (and subsequent decline) of this phenomenon in the US. While numerous observers noted that it was unlikely that this could be a result of the use of e-cigarettes of the kind that had been safely used for years, and the likelihood was that the issue was to do with vaping substances other than nicotine and common flavorings, most public health authorities issued urgent warning about ENDS use in general - and this was picked up around the world. It took several months for US authorities to effectively confirm the suspicion that these cases were associated with use of vaping equipment to inhale THC (an active component of cannabis).

The Center for Disease Control and Prevention (CDC) [CDC, 2019] announced that they had "identified vitamin E acetate as a chemical of concern among people with e-cigarette, or vaping, product use associated lung injury ... laboratory testing of ...fluid samples collected from the lungs...[of] patients ... found vitamin $\mathrm{E}$ acetate in all of the samples. Vitamin E acetate is used as an additive, most notably as a thickening agent in THC-containing e-cigarette, or vaping, products..."

By December 10, 2019, over 2,400 hospitalizations and over 50 deaths were reported by the $\mathrm{CDC}$, with new cases still emerging (though at a decreasing rate). According to CDC: "THCcontaining e-cigarette, or vaping, products, particularly from informal sources like friends, family, or in-person or online dealers, are linked to most of the cases and play a major role in the outbreak... Dank Vapes, a class of largely counterfeit THC-containing products of unknown origin, was the most commonly reported product brand used by patients nationwide."

Source: https://www.cdc.gov/tobacco/basic_information/e-cigarettes/severe-lung-disease.html\#what-is-new (по состоянию на 15.12.2019).

\section{Dates of symptom onset and hospital admission for patients with lung injury associated with e-cigarette use, or vaping in the United States, March 31-December 10, 2019}

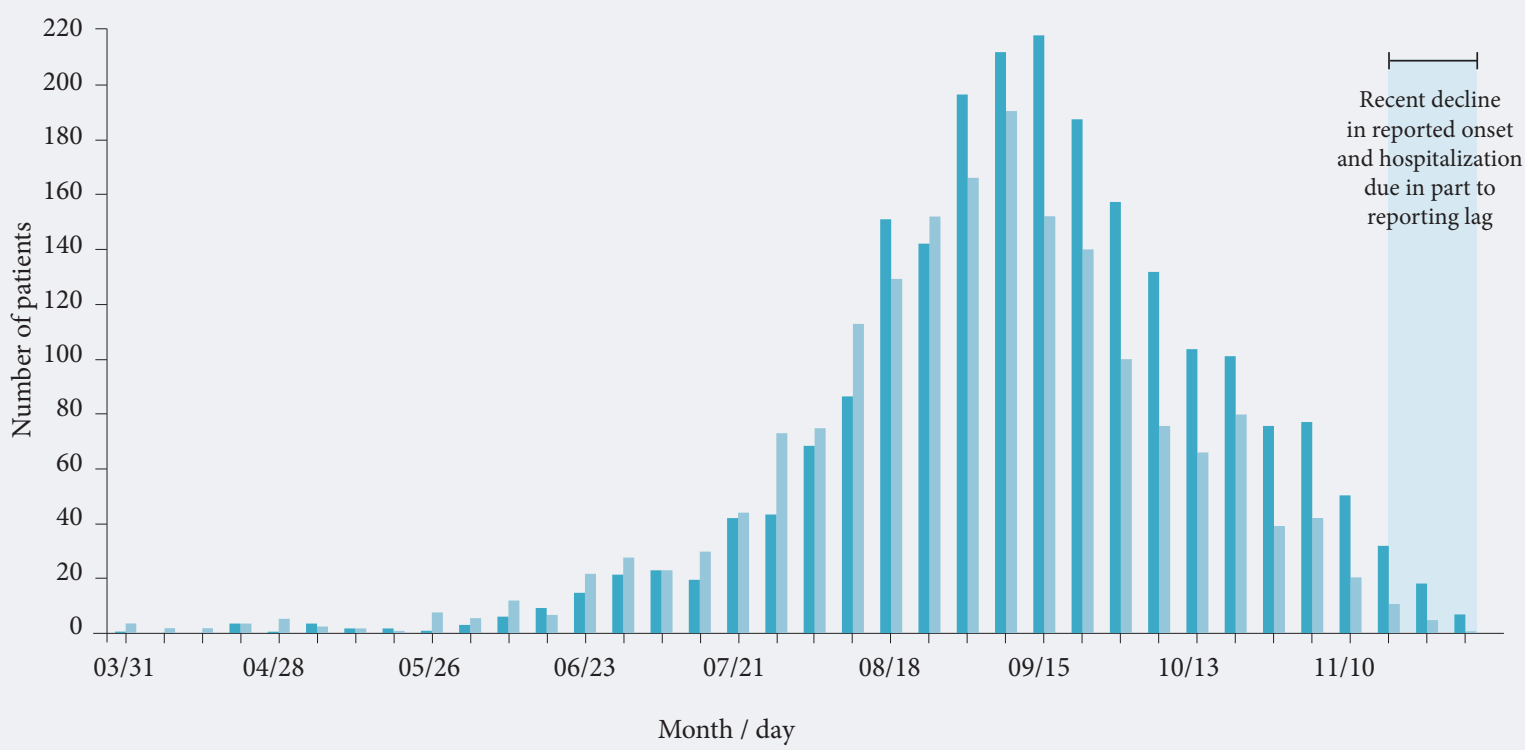

Source: https://www.cdc.gov/tobacco/basic_information/e-cigarettes/severe-lung-disease.html\#epi-chart (as of 15.12.2019). 
While the two key terms here are imperfect descriptors of the alternative philosophies, their use is ingrained and we will follow it below.

The prohibitionist, or abstentionist, point of view seeks to prevent the behavior that is associated with harm. Many cases concern a behavior with overtones of immorality - sexual promiscuity, drug abuse, driving above the speed limit. Risks associated with, for example, long-established sporting activities, are less often seen as requiring such an approach.

In the present case, prohibitionists stress the importance of tobacco control measures. They often see ENDS as a serious threat to the success of these measures (for reasons outlined in the body text). Some resistance to the disruptive innovation thus stems from quarters who are habitually aligned against the industries threatened with disruption. This is the mainstream position in many national and international public health bodies. Obstructive regulation could thus limit, or even suppress, the disruption.

The harm reduction point of view typically accepts that, even when discouraged (or even officially prohibited), many people will persist in undertaking risky practices. It highlights measures that can reduce the resulting harm. ${ }^{\mathrm{I}}$

Though the approach has a long history (for example, mandating automobile seatbelts and motorcycle helmets), the terminology of "harm reduction" rose to prominence with the AIDS crisis in the 1980s. Condom use would reduce the risks of sexual intercourse; needle exchange and related approaches would restrict spread within (and from) communities of intravenous drug users (cf. [Berridge, 1999]). The harm reduction approach has found many adherents in controversial areas of social and health policy such as sexual behavior and drugs - for a review of evidence and criticisms see [Hunt, 2003]. Harm reduction approaches to ENDS are outlined by [Polosa et al., 2013] (this paper also discusses snus, the innovative alternative to chewing tobacco).

An individual may well take a prohibitionist view of one topic, and a harm reduction view of another, and attitudes may be contingent upon the opportunities for enforcement of rules and for reduction of riskiness. However, tobacco control prohibitionists, such as Tobacco Tactics (an organization that investigates and documents the "strategies and tactics the tobacco industry uses to undermine public health") warn that:

"One of the reasons harm reduction is a sensitive topic is that it could involve engaging with the tobacco industry, which has a history of manipulating public debate and public health policy... To fully understand the harmfulness of potentially reduced risk products and their effectiveness for smoking cessation, tobacco industry investments and research into harm reduction and potentially reduced risk products should be carefully scrutinised... In fact, a number of scientists leading the debate on harm reduction and/or potentially reduced risk products are funded by the tobacco industry."II

Notes:

I Harm Reduction International hosts an annual conference on the field, and its website (https://www.hri.global/about) provides extensive documentation on the topic, with updates on the application of the approach (especially in relation to drug use) at https://www.hri. global/global-state-harm-reduction-2018 (accessed 24.11.2019). Much useful discussion on harm reduction in relation to ENDS is featured at the Nicotine Policy group at https://groups.google.com/ forum/\#!forum/nicotinepolicy (accessed 15/02/2020).

II Source: https://www.tobaccotactics.org/index.php?title=Harm Reduction (accessed 23.11.2019). nologies, long-term health consequences are yet to manifest themselves. Expert opinion on the relative risks of new products versus combustibles, discussed above, continues to be embedded into UK policies. However, debate has continued around the extent to which e-cigarettes may have dangers of their own. Especially where product quality has not been adequately regulated, it is likely that vapers may be inhaling unhealthy substances.
A number of deaths and injuries have been caused by exploding batteries and user modification of this component of e-cigarettes is reportedly involved in several cases [Equation, 2019]. ${ }^{24} \mathrm{~A}$ number of hospitalizations have arisen in the UK when drug dealers sold e-liquids that were claimed to feature cannabis, but instead were packed with a dangerous designer drug [Day, 2019]. A "wild card" arose in the United States in the summer of 2019 - a "mys-

${ }^{24}$ For discussions in user communities see also: https://www.e-cigarette-forum.com/threads/exploding-vape.896751/ (accessed 25.11.2019). 
tery vaping disease" resulted in thousands of cases of lung damage, and several deaths (see Box 3).

That third case against ENDS may apply less to $\mathrm{HNB}$, where there is less of a technological break with combustibles. However, a fourth set of reasons to oppose ENDS will apply equally to HNB. This time, the subject of stigma is not the tobacco industry, but nicotine itself. One fear is that nicotine use may damage young peoples' development (Is this not detectable from decades of youth smoking cigarettes?). But what looms large is concern about addiction. Even if it may not lead to the use of combustibles, and even if nicotine itself carries few health risks at typical levels of consumption, the existence of a nicotine "habit" is seen as inherently unpalatable.

Numerous commentators frame these divergent reactions to ENDS among the public health community as reflecting the clash of prohibitionist and harm reduction philosophies (see Box 4.) Such prohibitionist and harm reduction viewpoints have come into conflict in many arenas and nicotine products is one of the latest. This conflict of viewpoints makes e-cigarettes a distinctive case of disruptive innovation. The situation varies a great deal across countries and has been heavily influenced by reactions to events such as the "mystery vaping illness", which, as mentioned above, has a great deal to do with secondary innovations spawned around the disruptive innovation. The incumbents have, in many cases, sought to accommodate themselves to the innovation, by offering their own new products. However, resistance to the innovation has been mobilized by stakeholders who have ongoing opposition to the suppliers of the established product, which the innovation was threatening to displace. The potential disruption has polarized the debate between the two philosophies about how best to deal with the health risks of smoking.

This makes e-cigarettes a highly distinctive attempt at disrupted innovation. An unusual configuration of interests and philosophies have lined up in many countries to forestall this disruption. It may even be that radical change will be associated with a sustaining (?) innovation: HNB.

The future prospects for tobacco harm are, as we have implied above, highly uncertain. We have seen estimates of the death toll, and life years lost, if current trends continue and the effects of more or less substantial shifts to use of ENDS. With the divergence in policies and regulations across coun- tries, with numerous competing products emerging (not only ENDS, but also, for example, HNB and snus), and with competing viewpoints, this would seem to be an important topic for a Foresight study. What forms could such a study take?

\section{Foresight $^{25}$}

Foresight exercises address alternative futures and uncertainties. They engage experts and stakeholders to examine these alternatives and the scope for human agency to shape patterns of development. They go beyond forecasting and thus beyond the sort of modeling discussed earlier. In our case, estimates such as those of loss of lives and life-years in different scenarios, provided by modeling can be important inputs to a Foresight exercise. They give a quantitative dimension to scenario analysis and policy targets. Analyses such as those concerning the impacts of a shift to ENDS in the USA alone, could be valuably extended, ideally to cover the whole world, and drawing on data concerning plausible rates of adoption and cessation. Such analyses can also be valuable for benchmarking the circumstances of different countries.

\section{Focus}

Any Foresight exercise has a focus. This could be the overall question of future tobacco use, its impacts, and strategies for limiting its toll on human health. Alternatively, in line with many technology foresight exercises, it could focus specifically on disruptive innovation, considering how innovative products and practices might emerge and reshape the smoking landscape. Here it would be particularly important to consider not just the disruption of ENDS, but also what may be seen as the "sustaining" innovation of Heat-not-Burn, where products such as IQOS and Glo have succeeded in making inroads onto several markets. ${ }^{26}$ Though these have originated from big players in the tobacco industry, they radically differ from conventional combustibles, require change on the part of users as well as on the supply side, and may have considerable potential for harm reduction. Their social impacts are more significant than their attaining the status of "disruptive innovations".

The focus features a major topic and also has geographical and temporal dimensions: what locality, what time horizon? The focus usually reflects the sponsoring agency. Often these exercises are commissioned by national government agencies or by international bodies such as the European Com-

\footnotetext{
${ }^{25}$ The outline of Foresight activities presented here draws on the frameworks outlined in [Georghiou et al., 2008; Miles et al., 2016].

${ }^{26}$ Popular and user-oriented discussions of the different products and technologies are emerging online - see for example [Koshelev, 2019]. For a literature review on HNB use and health risks see [Simonavicius et al., 2019].
} 


\begin{tabular}{|c|c|}
\hline $\begin{array}{l}\text { Possible areas for } \\
\text { technological and } \\
\text { other types of } \\
\text { innovation }\end{array}$ & $\begin{array}{l}\text { - Conventional Cigarette products (e.g. novel additives, filters). } \\
\text { - Production of Combustibles (and production, e.g., automation, 3-D printing). } \\
\text { - ENDS designs and components (methods of vaporizing, sources of power, etc.) } \\
\text { - The liquids used to make vapors (flavors, aerosols, other ingredients). } \\
\text { - Alternative Recreational Products for Tobacco Users (new/improved noncombustible products such as e.g. } \\
\text { snus, heat-not-burn (HNB)). } \\
\text { - Alternatives to nicotine (e.g. new recreational drugs, or new practices that supplant nicotine use). } \\
\text { - Medical techniques for managing nicotine dependency (e.g. Nicotine Replacement Systems such as } \\
\text { patches). } \\
\text { - Medical techniques for reducing nicotine dependency (pharmaceuticals, vaccination, new } \\
\text { neuropsychology-based approaches, etc.). } \\
\text { - Psychological approaches to reducing nicotine dependency (Cognitive-behavioral therapy, hypnotherapy, } \\
\text { etc.; innovation here might include the use of new web-based support services, or wearable devices that } \\
\text { support healthy lifestyles). } \\
\text { - Tobacco Control Policies (new strategies and the use of new technology in public health campaigns, } \\
\text { restrictions on smoking and advertising). }\end{array}$ \\
\hline $\begin{array}{l}\text { Downstream } \\
\text { innovation }\end{array}$ & $\begin{array}{l}\text { - Medical approaches (or other techniques?) that could limit or correct one or more of the major harms } \\
\text { occasioned by tobacco use - and/or harm related to the use of new products for delivering nicotine. } \\
\text { - Changing medical criteria concerning the treatment of diseases occasioned by practices known to be risky } \\
\text { (e.g. restricting access to services for smokers). }\end{array}$ \\
\hline Upstream innovation & $\begin{array}{l}\text { - Tobacco agriculture (as impacted by climate change, new crop varieties, novel cultivation techniques) } \\
\text { - Activities related to agriculture (including distribution, storage of tobacco crops). } \\
\text { - Use of tobacco crops (use of other parts of the plant than are currently processed, applications for purposes } \\
\text { other than nicotine/cigarette production). } \\
\text { - Ways of producing nicotine (for example, large-scale, low-cost biosynthesis via modified yeast or bacteria). }\end{array}$ \\
\hline
\end{tabular}

Source: compiled by the author.

mission or one of its directorates. In many ways a multinational study that encompassed major world regions would be ideal - it could include areas with high cigarette usage, such as China, and countries with very different approaches to tobacco control and to harm reduction alternatives. For example, Sweden has interesting experience with snus and Japan with HNB. (One difficulty is that many organizations, e.g. WHO, already have strong positions on such innovations.) The time horizon could feature a relatively short-term examination or aim to look generations ahead. Given that technological innovations often take a couple of decades to diffuse widely ${ }^{27}$ and that the health impacts of cigarette smoking (and of ENDS?) unfold over an equally substantial period, it would make sense to cover at least the next twenty years.

\section{Scenarios}

Future prospects are highly uncertain, with numerous stakeholders are acting and reacting around the formulation and implementation of policies relating to tobacco control and to harm reduction (here we would include policies vis-à-vis ENDS, HNB, and similar new approaches to nicotine delivery).
One way of exploring such ideas is to undertake scenario workshops. There are many different scenario approaches [Miles et al., 2016] — one familiar approach would be to identify major drivers and uncertainties, and design scenarios around these. Another approach would start by identifying extreme (but plausible) outcomes, such as those in a 2-by-2 scenario framework, in which one dimension would involve extremes in the evolution of tobacco control aimed at cigarettes, one on extremes in the regulation of ENDS. The plausible extremes would be a matter for debate and resolution in the workshops that would examine what factors and forces might lead to such a pattern of development. Other workshop activities might involve attempting to simulate the responses of various stakeholders, with workshop members adopting "personas" representing different actors, how these might vary across countries and world regions, and in terms of outcomes for different social groups.

\section{Horizon-Scanning}

Scenario workshops are usefully informed by prior horizon-scanning activities. These might involve, literature reviews (State of the Science Reviews,

\footnotetext{
${ }^{27}$ Note that it is difficult to anticipate radical technological innovation more than a couple of decades hence, since this will often involve breakthroughs in knowledge that have yet to take place.
} 
Bibliometric analyses, etc.) or more active elicitation of expert opinion by means, say, of Delphi surveys. One of the major purposes of such scanning is to examine the scope for technological (and social) innovations that could be important determinants of developments in the field. These might involve innovative products, production processes, social practices, regulations and regulatory systems, and new ways of measuring and monitoring activities and outcomes.

Table 1 illustrates the wide range of topics that could be examined here. Such a panoply of developments is exactly the sort of complex evolving landscape that we confront in many technology Foresight studies. A literature review may identify emerging possibilities for innovation in the various areas. Additionally, expert knowledge and creativity mobilized in, for example, brainstorming workshops and/or by the use of systematic creativity techniques could well pinpoint prospects that can be deduced from thinking about other lines of work. Once identified, key innovations can be addressed through workshops, Delphi surveys, and the like. For example, a Delphi survey could be organized to ask informed individuals about each innovation: how near it is to realization, when it might be launched, what the impacts would be (for example, health outcomes as well as other social and economic costs and benefits), what factors might facilitate or inhibit development, and so on.

Appraising future markets and regulations involves the analysis of key drivers, for example using STEEPV. Such factors may well vary across (and within): they include social trends (such as the conditions that may lead to a desire for stress relief, attitudes toward the use of psychotropic drugs, and levels of concern about health and lifestyle) as well as economic and political factors (among which the incomes governments derive from the tobacco tax may be important, while in some countries the links between tobacco industry and the state may be very strong - to the point where large cigarette manufacturers may be state-owned ). Again, such developments can be addressed through media analysis, literature review, and the elicitation of expert opinions.

\section{Wild Cards}

Such enquiries would normally proceed before, and inform, scenario analysis. It will also be important in the course of such work to pay attention to wild cards - things that are not expected to have a probability of more than 1 in 10 of coming about, but that would have an immense impact if they did. The "mystery vaping illness" of the summer of 2019 (see Box 3) combines two topics where early warning signals were already apparent. First is the use of vaping systems for inhaling drugs other than nicotine. It is not uncommon for complementary and user innovations to be "wild cards" for the initial innovator, substantially changing the way in which their products may be used, and the cultural meanings they acquire. Second, is the emergence of unexpected health risks (apparently) linked to ENDS. The suddenly emerging wild card involved the fusion of these two topics. Mass media and politicians interpreted the damage done by illicit vaping activities as indicative of a danger in all e-cigarettes. Not only did it seemingly confirm fears about vaping being potentially harmful, but at the same time there was much media coverage about teenage vaping "epidemic". Concerns about the "mystery vaping illness" intersected with those about "a large increase in the proportion of high schoolers who reported any vaping in the past 30 days, from $11.7 \%$ in 2017 to $27.5 \%$ in 2019" in the USA [Fairchild et al., 2019, p. 1319]. The response there and in several other countries has been restrictions on flavorings that are believed to appeal to young people in particular, and other moves to restrict ENDS use. ${ }^{28}$ Ironically, it is plausible that potential users may have been motivated by the health scare to explore HNB devices instead of ENDS.

Further wild cards are likely to arise and hindsight will subsequently portray them as less "wild" than originally thought. Foresight discussions often throw up possible wild cards, but they can also be deliberately focused on. STEEPV can be used as a framework to brainstorm wild possibilities, and workshops can explore their implications. Experience suggests that, while we can often successfully identify wild card events, the specific manifestation of a wild card, and the cascading reactions of social actors, may take quite different forms from those envisaged. A whole pack of wild cards may ensue, leading to outcomes that can be highly dependent on the precise intensities and sequences of events.

These are among the most challenging aspects of Foresight studies - so much so that a distinct field of work on "risk assessment" has been developed to examine catastrophic wild cards, including also those phenomena believed likely to happen but with highly uncertain timing (extreme natural phenomena, from earthquakes to Carrington Eventtype solar storms ${ }^{29}$, are often of this type). Human

\footnotetext{
${ }^{28}$ Among recent press reports, one that discusses pressure on UK regulators is [Waldie, 2019].

${ }^{29}$ It is believed that a repeat of the Carrington Event of 1859, which created beautiful auroral displays but disrupted telegraph systems, would severely damage global electrical and communications networks. An approach to estimate the likelihood of such an event in coming decades is proposed by [Morina et al., 2019].
} 
history has been punctuated by wild cards. But it is impracticable to examine more than a fraction of the possible wild cards that can be anticipated in any detail - especially given that there are a myriad of ways in which any wild card might be realized. A few may be selected for risk assessment exercises. Others can be taken into account when developing early warning systems to monitor developments in the field over the following years.

\section{Action}

Later steps in Foresight exercises involve developing proposals for policies and strategies for stakeholders to purse, in order to achieve desirable futures. Various procedures can be implemented in order to generate and prioritize such options, with roadmapping techniques being useful for sequencing them. While roadmapping is generally used to identify steps towards a future whose desirability is a matter of some consensus, it is also possible to use such approaches to examine actions that might be required in the event that alternative scenarios materialize.

It is important to engage participants knowledgeable about such issues as the scheduling and phraseology of policies, the instruments available to different actors, and the extent to which stakeholders can be persuaded to deal with long-term prospects. In this controversial field it may be that it is difficult to achieve consensus, for example a prohibition/abstinence perspective and a harm reduction one may remain opposed even as concerns the longer term. Even so, dialogue between the op- posing viewpoints - which may require a facilitator skilled in conflict - may be of value to all sides, in deepening their understanding of the relevant arguments, counterarguments, hopes, and fears.

A Foresight activity focused on tobacco futures and/or on the scope for disruptive innovation here, would seem to be well worthwhile. We are dealing with an activity involving expenditures of billions of dollars, and threats to many millions of lives. What would be important for such an exercise would be for it to be championed by an "honest broker", that is, one not seen as seeking to impose one or the other agenda on the process and who could engage those whose expertise is vital for the success of the process. Who will step up to this task?

The present article draws on outputs from the preliminary scoping of an envisaged multi-country Foresight exercise. Ian Miles was funded in late 2018-early 2019 by the Foundation for a Smoke-Free World (FSFW).30 FSFW received funding from a tobacco firm (Philip Morris International) and though it has documented its independence and governance,31 Tobacco Tactics considers it a "front organization" for the tobacco industry,32 and some correspondents to The Lancet recently proclaimed: "Now, more than ever, we must reinforce the hitherto successful calls from WHO and the public health community to reject collaboration with the Foundation" [Legg et al., 2019, p. 2478]. Preparatory work found that much wariness exists among potential collaborators in the Foresight study. The study got partial funding under the NRU HSE Basic Research Program and the "5-100" Program. The author is responsible for opinions presented in this essay.

\section{References}

ASH (2019) Use of e-cigarettes (vaporizers) among adults in Great Britain, London: Action on Smoking and Health. Available at: https://ash.org.uk/wp-content/uploads/2019/09/Use-of-e-cigarettes-among-adults-2019.pdf, accessed 13.10.2019.

Aveyard C., Raw M. (2012) Improving smoking cessation approaches at the individual level. Tobacco Control, vol. 21, no 2, pp. 252-257.

Bell K., Keane H. (2014) All gates lead to smoking: The 'gateway theory', e-cigarettes and the remaking of nicotine. Social Science \& Medicine, vol. 119, pp. 45-52.

Bero L. (2013) Tobacco industry manipulation of research. Late lessons from early warnings: Science, precaution, innovation (eds. D. Gee, P. Grandjean, S. Foss Hansen, S.van den Hove), Copenhagen: European Environmental Agency, pp. 151178. Available at: https://www.eea.europa.eu/publications/late-lessons-2, accessed 14.02.2020.

Berridge V. (1999) Histories of Harm Reduction: Illicit Drugs, Tobacco, and Nicotine. Substance Use \& Misuse, vol. 34, no 1 , pp. 35-47.

Brehmer Z., Boumphrey S. (2019) How to Be a Disruptive Brand: Reinventing Consumer Markets, London: Euromonitor International. Available at: https:/go.euromonitor.com/white-paper-ec-2019-how-to-be-a-disruptive-brandreinventing-consumer-markets.html, accessed 23.09.2019.

CDC (2019) Outbreak of Lung Injury Associated with the Use of E-Cigarette, or Vaping, Products, Washington, D.C.: Center for Disease Control and Prevention. Available at: https://www.cdc.gov/tobacco/basic_information/e-cigarettes/severelung-disease.html, accessed 22.11.2019.

\footnotetext{
${ }^{30}$ https://www.smokefreeworld.org (accessed 17.12.2019).

${ }^{31}$ See documents at https://www.smokefreeworld.org/governance/ (accessed 15.02.2020).

${ }^{32}$ https://www.tobaccotactics.org/index.php?title=Category:Front_Groups (accessed 17.12.2019).
} 
Chapman S., Wakefield M.A. (2013) Large-scale unassisted smoking cessation over 50 years: Lessons from history for endgame planning in tobacco control. Tobacco Control, vol. 22, no 1, pp. 33-35.

Chen J., Bullen C., Dirks K. (2017) A Comparative Health Risk Assessment of Electronic Cigarettes and Conventional Cigarettes. International Journal of Environmental Research and Public Health, vol. 14, no 4, article 382 (online). DOI: 10.3390/ijerph14040382. Available at: https://www.ncbi.nlm.nih.gov/pmc/articles/PMC5409583/, accessed 12.12.2019.

Christensen C.M., Raynor M.E. (2003) The Innovator's Solution: Creating and Sustaining Successful Growth, Cambridge, MA: Harvard Business School Press.

Christensen C.M. (1997) The Innovator's Dilemma: When New Technologies Cause Great Firms to Fail, Cambridge, MA: Harvard Business School Press.

Christensen C.M. (2006) The ongoing process of building a theory of disruption. Journal of Product Innovation Management, vol. 23, pp. 39-55.

Danneels E. (2004) Disruptive technology reconsidered: A critique and research agenda. Journal of Product Innovation Management, vol. 21, pp. 246-258.

Day R. (2019) Kids thought this was 'natural cannabis' vape juice... it was Spice. Nine people who ended up in hospital could have died. Available at: https://www.manchestereveningnews.co.uk/news/greater-manchester-news/kids-thoughtnatural-cannabis-vape-16591853, accessed 25.11.2019.

Djurdjevic S., Sponsiello-Wang Z., Lee P.N., Fry J.S., Weitkunat R., Lüdicke F., Baker G. (2018) Modeling the impact of changes in tobacco use on individual disease risks. Regulatory Toxicology and Pharmacology, vol. 87, pp. 88-97. DOI: $10.1016 /$ j.yrtph.2018.06.001.

Equation D. (2019) Why Do Vapes Explode? The \#1 Most Common Reason (And How to Avoid It). Available at: https:// vapebeat.com/vape-user-guides/why-do-vapes-explode, accessed 25.11.2019.

Etter J.-F. (2017) Gateway effects and electronic cigarettes. Addiction, vol. 113, no 10, pp. 1776-1783. DOI: 10.1111/ add.13924.

Fairchild A., Healton C., Curran J., Abrams D., Bayer R. (2019) Evidence, alarm, and the debate over e-cigarettes. Science, no 366 (6471), pp. 1318-1320.

Freeman C. (1975) The Economics of Industrial Innovation, Harmondsworth: Penguin.

FSFW (2018) Global Trends in Nicotine, New York: Foundation for a Smoke-Free World. Available at: https://www. smokefreeworld.org/sites/default/files/fsfw-report-trends-in-nicotine-1005201811.pdf, accessed 18.11.2019.

GBD (2017) Smoking prevalence and attributable disease burden in 195 countries and territories, 1990-2015: A systematic analysis from the Global Burden of Disease Study 2015. Lancet, no 389 (10082), pp.1885-1906. DOI: 10.1016/S01406736(17)30819-X.

Georghiou L., Cassingena Harper J., Keenan M., Miles I., Popper R. (eds.) (2008) The Handbook of Technology Foresight, Cheltenham, UK; Northampton, MA, USA: Edward Elgar.

Horwitz J. (2019) China's tobacco monopoly means big risks for e-cigarette startups. Available at: https://www.reuters. com/article/us-china-ecigarettes-insight/chinas-tobacco-monopoly-means-big-risks-for-e-cigarette-startupsidUSKBN1XH0LW, accessed 17.11.2019.

Hunt N. (2003) A review of the evidence-base for harm reduction approaches to drug use, London: Forward Thinking on Drugs Initiative. Available at: https://www.hri.global/files/2010/05/31/HIVTop50Documents11.pdf, accessed 24.11.2019.

ITC (2017) International Tobacco Control (ITC) Policy Evaluation Project. China Executive Summary Report. Findings from the Wave 1 to 5 Surveys (2006-2015), Waterloo, ON: Canada University of Waterloo; Beijing, China: Tobacco Control Office, Chinese Center for Disease Control and Prevention.

Jones L. (2019) Vaping: How popular are e-cigarettes? Available at: https://www.bbc.co.uk/news/business-44295336, accessed 13.10.2019.

Juma C. (2016) Innovation and Its Enemies: Why People Resist New Technologies, New York: Oxford University Press.

Kirton D. (2019) China may roll out e-cigarette rules amid global vaping backlash: State media. Available at: https://www. reuters.com/article/us-china-ecigarettes-idUSKBN1W9141, accessed 17.11.2019.

Koshelev D. (2019) Big comparison of tobacco heating devices: IQOS and glo vs Pod-systems: Logic Compact, JUUL, Joint. Available at: https://root-nation.com/gadgets-en/en-tobacco-heating-devices-and-nicotine-salts/, accessed 17.12.2019.

Kyriakoudes L.M. (2006) "Historians' testimony on "common knowledge" of the risks of tobacco use: A review and analysis of experts testifying on behalf of cigarette manufacturers in civil litigation. Tobacco Control, vol. 15, no 4, pp. 107-116.

Lee P.N., Fry J.S., Hamling J.F., Sponsiello-Wang Z., Baker G., Weitkunat R. (2017) Estimating the effect of differing assumptions on the population health impact of introducing a Reduced Risk Tobacco Product in the USA. Regulatory Toxicology and Pharmacology, vol. 88, pp. 192-213. DOI: 10.1016/j.yrtph.2017.06.009. 
Legg T., Peeters S., Chamberlain P., Gilmore A.B. (2019) The Philip Morris-funded Foundation for a Smoke-Free World: Tax return sheds light on funding activities. Lancet, no 393(10190), pp. 2487-2488. Available at: https://www.thelancet. com/journals/lancet/article/PIIS0140-6736(19)31347-9/fulltext, accessed 24.11.2019.

Levy D.T., Borland R., Lindblom E.N., Goniewicz M.L., Meza R., Holford T.R., Yuan Z., Luo Y., O’Connor R.J., Niaura R., Abrams D.B. (2018) Potential deaths averted in USA by replacing cigarettes with e-cigarettes. Tobacco Control, vol. 27, no 1 , pp. $18-25$.

Li C. (2012) The Political Mapping of China's Tobacco Industry and Anti-Smoking Campaign, Washington: Brookings Institution. Available at: https://www.brookings.edu/wp-content/uploads/2016/06/25-china-tobacco-li.pdf, accessed 17.11.2019.

Mathers C.D. (2018) New Projections of Mortality and Causes of Death to Year 2060. Available at: https://colinmathers. com/2018/11/14/new-projections-of-mortality-and-causes-of-death-to-year-2060/2 accessed 07.10.2019.

Mathers C.D., Loncar D. (2006) Projections of global mortality and burden of disease from 2002 to 2030. PLoS Medicine, vol. 3, no 11, article e442, pp. 2011-2030.

McNeill A., Brose L.S., Calder R., Bauld L., Robson D. (2019) Vaping in England: An evidence update February 2019, London: Public Health England. Available at: https://assets.publishing.service.gov.uk/government/uploads/system/uploads/ attachment_data/file/821179/Vaping_in_England_an_evidence_update_February_2019.pdf, accessed 12.10.2019.

McNeill A., Brose L.S., Calder R., Bauld L., Robson D. (2018) Evidence review of e-cigarettes and heated tobacco products 2018. A report commissioned by Public Health England, London: Public Health England.

Miles I., Saritas O., Sokolov A. (2016) Foresight for Science, Technology and Innovation, Heidelberg, New York, Dordrecht, London: Springer.

Moriña D., Serra I., Puig P., Corral A. (2019) Probability estimation of a Carrington-like geomagnetic storm. Nature Scientific Reports, vol. 9, report 2393. Available at: https://www.nature.com/articles/s41598-019-38918-8, accessed 11.12.2019.

Mylan J., Morris C., Beech E., Geels F.W. (2019) Rage against the regime: Niche-regime interactions in the societal embedding of plant-based milk. Environmental Innovation and Societal Transitions, vol. 31, pp. $233-247$.

NASEM (2018) Public Health Consequences of E-Cigarettes. National Academies of Sciences, Engineering, and Medicine (NASEM) Report 2018, Washington, D.C.: National Academies of Sciences. Available at: http://nationalacademies.org/ hmd/Reports/2018/public-health-consequences-of-e-cigarettes.aspx, accessed 15.11.2019.

Newsweek (2015) Big Tobacco Fights Back: How The Cigarette Kings Bought The Vaping Industry. Available at: https://www. newsweek.com/big-tobacco-fights-back-how-cigarette-kings-bought-vaping-industry-327758, accessed 27.11.2019.

Nutt D.J., Phillips L.D., Balfour D., Curran V.H., Dockrell M., Foulds J., Fagerstrom K., Letlape K., Polosa R., Ramsey J., Sweanor D. (2016) E-cigarettes are less harmful than smoking. Lancet, no 387 (10024), pp. 1160-1162. DOI: 10.1016/ S0140-6736(15)00253-6. Available at: http://eprints.lse.ac.uk/66173/1/Phillips_E-cigarettes\%20are\%20less\%20 harmful\%20than\%20smoking.pdf, accessed 17.10.2019.

Nutt D.J., Phillips L.D., Balfour D., Curran H.V., Dockrell M., Foulds J., Fagerstrom K., Letlape K., Polosa R., Ramsey J., Sweanor D. (2014) Estimating the harms of nicotine-containing products using the MCDA approach. European Addiction Research, vol. 20, pp. 218-225.

Parker-Pope T. (2001) Cigarettes: Anatomy of an Industry from Seed to Smoke, New York: Free Press.

Phillips C.V. (2015) Gateway Effects: Why the Cited Evidence Does Not Support Their Existence for Low-Risk Tobacco Products (and What Evidence Would). International Journal of Environmental Research and Public Health, vol. 12, no 5, pp. 5439-5464.

Polosa R., Rodu B., Caponnetto P., Maglia M., Raciti C. (2013) A fresh look at tobacco harm reduction: The case for the electronic cigarette. Harm Reduction Journal, vol. 10, no 19 (online). Available at: http://www.harmreductionjournal. com/content/10/1/19, accessed 04.03.2019.

Rossheim M.E., Livingston M.D., Soule E.K., Zeraye H.A., Thombs D.L. (2019) Electronic cigarette explosion and burn injuries, US Emergency Departments 2015-2017. Tobacco Control, vol. 28, no 4, pp. 472-474.

Ruegg T.A. (2015) Historical Perspectives of the Causation of Lung Cancer: Nursing as a Bystander. Global Qualitative Nursing Research, vol. 2, article 2333393615585972 (online). Available at: https://www.ncbi.nlm.nih.gov/pubmed/28462309, accessed 23.11.2019.

Simonavicius E., McNeill A., Shahab L., Brose L.S. (2019) Heat-not-burn tobacco products: A systematic literature review. Tobacco Control, vol. 28, pp. 582-594. DOI: 10.1136/tobaccocontrol-2018-054419.

Song M., Benowitz N.L., Berman M., Brasky T.M., Cummings K.M., Hatsukami D.K., Marian C., O’Connor R., Rees V.W., Woroszylo C., Shields P.G. (2017) Cigarette filter ventilation and its relationship to increasing rates of lung adenocarcinoma. Journal of the National Cancer Institute, vol. 109, no 12, article PMC6059254 (online). DOI: 10.1093/ jnci/djx075. Available at: https://www.ncbi.nlm.nih.gov/pmc/articles/PMC6059254/, accessed 14.10.2019. 
Spielman A., Azer V. (2013) E-cigarettes. Disruptive Innovation: Ten Things to Stop and Think About. Disruptive Innovation Series, issue 1. New York: Citigroup. Available at: https://www.citivelocity.com/citigps/disruptive-innovation/, accessed 23.10.2019.

Stephens W.E. (2018) Comparing the cancer potencies of emissions from vaporized nicotine products including e-cigarettes with those of tobacco smoke. Tobacco Control, vol. 27, no 1, pp. 10-17.

Stratton K., Shetty P., Wallace R., Bondurant S. (eds.) (2001) Clearing the Smoke: Assessing the Science Base for Tobacco Harm Reduction, Washington, DC: The National Academies Press.

Surgeon General (2016) E-Cigarette Use Among Youth and Young Adults: A Report of the Surgeon General, Rockville, MD: U.S. Department of Health and Human Services, Public Health Service Office of the Surgeon General.

UK ONS (2019) Adult smoking habits in the UK: 2018, London: HMSO Office for National Statistics. Available at: https:// www.ons.gov.uk/peoplepopulationandcommunity/healthandsocialcare/healthandlifeexpectancies/bulletins/adultsmoki nghabitsingreatbritain/2018\#toc, accessed 13.10.2019.

Usbourne S. (2018) Squonkers, drippers and cloud chasers: The rise of vape culture. Available at: https://www.theguardian. com/society/2018/jun/09/vape-culture-squonkers-drippers-cloud-chasers-simon-usborne, accessed 02.11.2019.

Waldie P. (2019) Growing backlash against vaping in Canada, U.S. raises public-health concerns in Britain. Available at: https://www.theglobeandmail.com/canada/article-growing-backlash-against-vaping-in-canada-us-raises-publichealth/, accessed 25.11.2019.

Warner K.E., Mendez D. (2019) E-cigarettes: Comparing the Possible Risks of Increasing Smoking Initiation with the Potential Benefits of Increasing Smoking Cessation. Nicotine \& Tobacco Research, vol. 21, no 13, pp. 41-47.

WHO (2016) Electronic Nicotine Delivery Systems and Electronic Non-Nicotine Delivery Systems (ENDS/ENNDS). Report no FCTC/COP/7/11, Geneva: World Health Organization. Available at: https://www.who.int/fctc/cop/cop7/FCTC_ COP_7_11_EN.pdf, accessed 18.11.2019.

WHO (2008) WHO Report on the Global Tobacco Epidemic, Geneva: World Health Organization. Available at: https://www. who.int/tobacco/mpower/2008/en/, accessed 04.10.2019.

Williams M., Talbot P. (2019) Design Features in Multiple Generations of Electronic Cigarette Atomizers. International Journal of Environmental Research and Public Health, vol.16, no 16, article 2904. DOI: 10.3390/ijerph16162904. Available at: https://www.ncbi.nlm.nih.gov/pmc/articles/PMC6720609/, accessed 19.11.2019.

Wolters A. (2017) The Vaccination of 'Unhealthy' Lifestyles? (PhD Thesis), Maastricht: University of Maastricht. Available at: https://waw.nu/wp-content/uploads/2017/11/Anna-Wolters-2017-Dissertation-The-vaccinisation-of-unhealthylifestyles.pdf, accessed 09.10.2019. 